\title{
Original
}

\section{Quantitative Radiographic Study of New Bone Formed Around The Implant Using a Parametric X-ray Method}

\author{
Taketoshi Suwa ${ }^{1,2)}$, Toshiro Sakae ${ }^{3)}$, Hiroshi Nakada ${ }^{2)}$, Yasuko Numata ${ }^{4)}$ and Isamu Sato ${ }^{1)}$
}

\author{
${ }^{1)}$ Laboratory for Electron Beam Research and Application, Nihon University \\ 2) Gnatho-Oral Prosthetic Rehabilitation, Nihon University School of Dentistry at Matsudo \\ 3) Department of Histology, Cytology and Development, Nihon University School of Dentistry at Matsudo \\ 4) Complete Denture Prosthodontics, Nihon University Graduate School of Dentistry at Matsudo \\ (Accepted for publication, October 24 , 2007)
}

\begin{abstract}
Bone formed around implant was characterized and grouped into three categories by Nakada et al. ${ }^{1,2)}$ and Suwa et al. ${ }^{3)}$. In order to clarify these bone tissues, we have utilized radiography with a newly developed wavelength tunable and highly parallel Parametric X-ray (PXR) in the Laboratory for Electron Beam Research and Application (LEBRA) of Nihon University. Methods: Ti-alloy implants modified with coating or blasting were used in this study. These materials were implanted in the tibia of rabbits. After 1, 2 and 4 weeks of implantation, non-demineralized polished thin sections were cut. PXR was generated by a LINAC in the LEBRA of Nihon University. X-ray wavelength was tuned from $7 \mathrm{KeV}, 0.177 \mathrm{~nm}$ to $16 \mathrm{KeV}, 0.0775 \mathrm{~nm}$; irradiation: 900 sec; sample-detector distance: $7.5 \mathrm{~mm}$ and recording film: Fuji Film Imaging Plate. The obtained images were processed by NIH image analyzer. Results: PXR radiography showed the clear difference between the newly formed bone and the compact bone. Estimated percentage for the newly formed and pre-existing bone were $8.27 \%$ and $20.9 \%$, respectively. Conclusion: LEBRA-PXR could be a good tool for the quantitative analysis of bone formation.
\end{abstract}

Key words: LEBRA-PXR, Implants, Rabbit tibia

\section{Introduction}

Osseointegration of implants has been the subject of many investigations. Nakada et al. ${ }^{1)}$ classified the newly formed bone around and/or attached to Ti alloy implanted in rabbit tibia into three categories: (a) closely attached to the compact bone, (b) surrounding the implant and (c) occurring at the bone marrow spaces or medullary cavities These authors carefully investigated these bones using polarized light microscopy and Roentgen microradiography. Moreover, we have previously reported crystallographic differences in the newly formed bones ${ }^{2,3)}$.

The aim of this study was to determine structural and histological differences of these bones using a newly developed wavelength tunable Parametric X-ray, PXR.

\section{Materials and Methods}

Animal experiment: thirteen-weeks-old New Zealand White rabbits were used in this study according to the Experimental Animal Ethics Committee (ECS-02-0019) of the Nihon University School of Dentistry at Matsudo. Titanium alloy (Ti-6Al-4V) of $2.8 \mathrm{~mm}$ in diameter and $8.0 \mathrm{~mm}$ in length, and grid-blasted with alumina powder abrasive were implanted in the tibia of rabbits

Corresponding author: Taketoshi Suwa, Department of Gnatho-Oral Prosthetic Rehabilitation, Nihon University School of Dentistry at Matsudo Sakaecho-nishi, Mataudo, Chiba 271-8587, Japan Phone: +81-47-3609376, Fax: +81-47-360-9376, E-mail: suwa.taketoshi@nihon-u.ac.jp
(Fig. 1). After 1, 2 and 4 weeks of implantation, the animals were sacrificed under anesthesia. Non-demineralized polished sections were cut at $160 \mu \mathrm{m}$ in thickness.

Parametric X-ray experiment: Parametric X-ray (PXR) is an emergent $\mathrm{X}$-ray, which can be generated by irradiating electrons to a crystal. Laboratory for Electron Beam Research and Application (LEBRA) of Nihon University succeeded in generating PXR using a $100 \mathrm{MeV}$ LINAC and applying it to several kinds of X-ray experiments (Fig. 24) ${ }^{4-6)}$. PXR has many unique characteristics, the most important of which is tunable highly coherent and highly monochromatized X-ray wavelength $(\mathrm{nm})$, or X-ray energy $(\mathrm{KeV})$. X-ray attenuation of material varies depending on the wavelength, causing changes in radio-opacity. The interested area, for example bone tissues in this study, can be distinguished by selecting the X-ray wavelength. Imaging Plate, Fuji film Co., was used in this study for its wide dynamic range and fine linearity.

The estimated apatite content was calculated using the equation: $\mathrm{V}_{\mathrm{HA}}=8.4 \times 10^{-4} \times \mathrm{n} / \mathrm{t} \times 100 \times 20 / 17$, where $\mathrm{V}_{\mathrm{HA}}=$ volume of hydroxylapatite, $\mathrm{n}=$ number of aluminum foil and $\mathrm{t}=$ thickness of section $^{7}$.

\section{Results}

Fig. 3 showed the effects of PXR wavelength variation to the recorded images. Ti-implant was clearer detected with the increase 
Taketoshi Suwa et al.: Quantitative Radiography of Bones around The Implant Using a Parametric X-ray

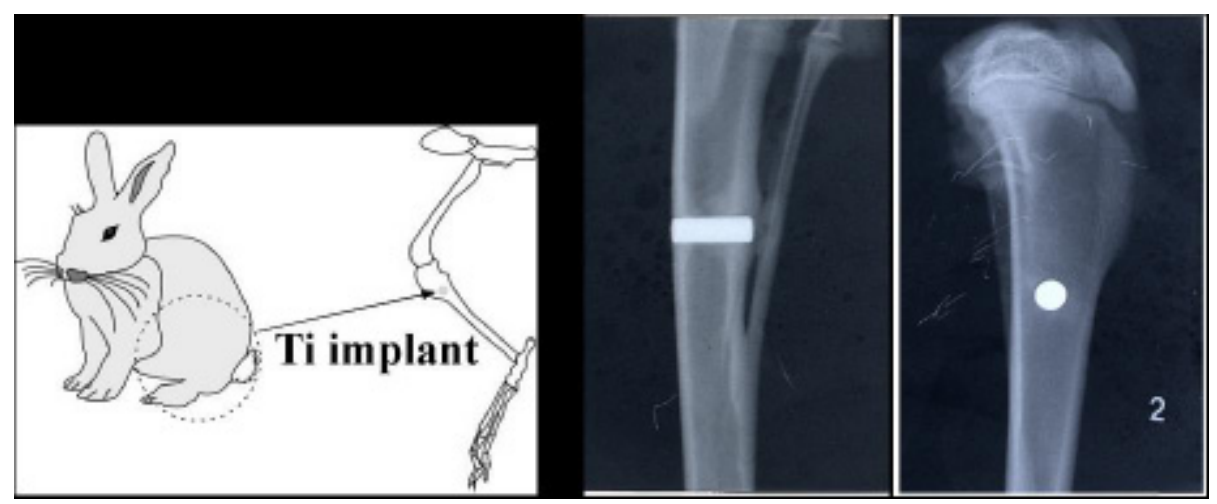

Fig. 1 (Left) Schematic representation of Ti-implant in the tibia of rabbit. (Right) Roentgen images of the newly formed bone? ${ }^{3)}$.

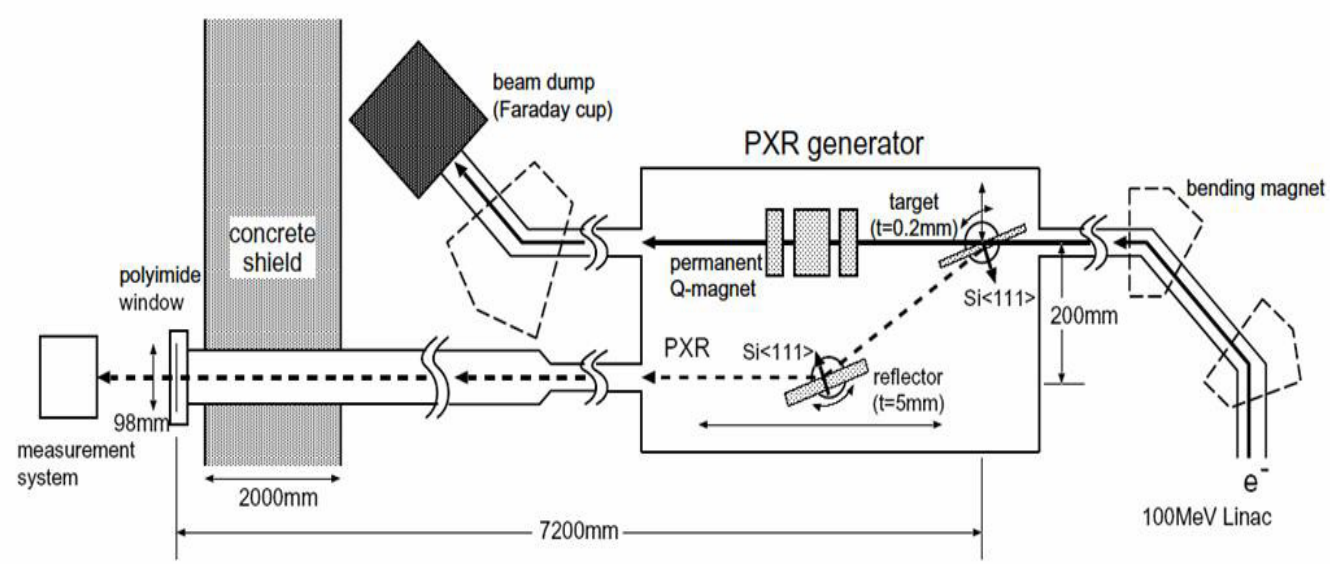

Fig. 2 Schematic representation of generation of wavelength tuneable Parametric X-ray, PXR ${ }^{5}$.
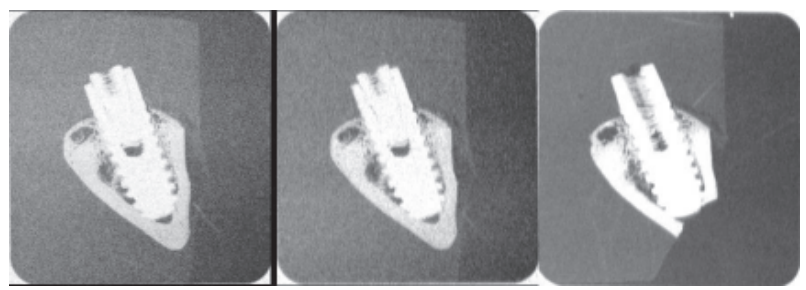

Fig. 3 Wavelength dependent radio-opacity. Note the Ti-implant was clearer detected with the increase in X-ray energy. (From left to right: $15 \mathrm{KeV}, 16$ $\mathrm{KeV}, 17 \mathrm{KeV}$ )

in X-ray energy from $15 \mathrm{KeV}(0.0827 \mathrm{~nm})$ to $17 \mathrm{KeV}(0.0730$ $\mathrm{nm}$ ). In general, the higher X-ray energy means higher potential of X-ray penetration through material. Therefore, more radiotranslucency was observed using the $17 \mathrm{KeV}$ PXR than using the $15 \mathrm{KeV}$ PXR.

Fig. 4 shows a Roentgen image of the newly formed bone using the PXR. In this figure the three categories of newly formed bone are clearly distinguishable: closely attached to the compact bone, surrounding the implant and occurring at the bone marrow spaces or medullary cavities.

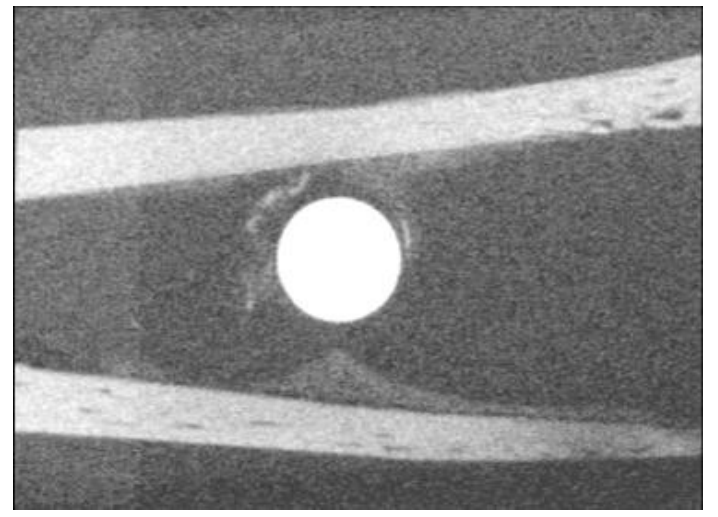

Fig. 4 PXR micro-radiogram of the Ti-implant in rabbit tibia bone section. Difference in radio-opacity for the newly formed bone tissues was clearly shown.

Fig. 5 shows the result of a quantitative analysis of the recorded image. In this study, we followed a quantitative calculation of the degree of calcification from the X-ray micro-radiogram previously reported by Suga and Sakae et al. ${ }^{8,9)}$, the degree of radio-opacity was converted to estimated hydroxyapatite $\%$ ? content with the 
J.Hard Tissue Biology Vol. 16(3):139-141,2007

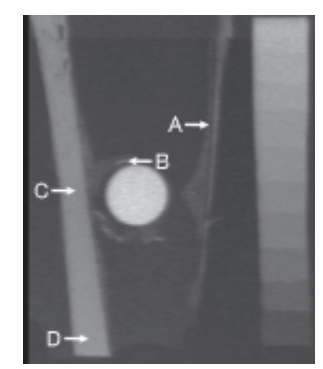

Fig. 5 Gray-scaled representation of Ti-implant in rabbit tibia bone. Aluminium step-wedge was located beside as for X-ray attenuation standard.

help of the aluminum step-wedge. The estimated apatite content in the newly formed bone was 8.27-20.9\%, and those for the preexisting compact bone was 34.1-43.0\%.

\section{Discussion}

LEBRA-PXR allows controlled changes of the highly monochromatized X-ray wavelength easily. As shown in Fig. 2, radio-opacity of the material was dependent on the $\mathrm{X}$-ray wavelength used. In contrast, using a standard dental Roentgen system, the fine structures shown in Fig. 3 could not be distinguished ${ }^{1)}$. The clear images obtained by PXR were due not only to the highly monochromatized but also highly-ordered parallel X-ray beam which did not cause obscure images.

The monochromatized $\mathrm{X}$-ray has an advantage in quantitave analysis of the degree of calcification of bone. In contrast, using $\mathrm{X}$-rays from usual generators which contain several characteristic $\mathrm{X}$-rays or white $\mathrm{X}$-rays, some special instrument, such as graphite monochrometer, is required to obtain monochromatized X-ray ${ }^{9)}$. For that reason, the combination of the wavelength tuneablity and monochromatized character of PXR could provide a quick and precise quantitative radiographic analyzer.

\section{Conclusion}

LEBRA-PXR demonstrated a good resolution for radiographic analysis in the bone of rabbit. The high-power, highly monochromatized and highly parallel oriented X-ray resulted in an easy radiographic analysis including quantitative analysis.
Table 1 The estimated apatite content.

\begin{tabular}{ccccc}
\hline & $\mathrm{A}$ & $\mathrm{B}$ & $\mathrm{C}$ & $\mathrm{D}$ \\
\hline $\mathrm{V}_{\text {(НА) }}$ & 8.27 & 20.9 & 34.1 & 43.0 \\
\hline
\end{tabular}

\section{Acknowledgements}

The authors thank to the members of LEBRA at Nihon University for their help. This study was supported in part by the Grant-inAid for Scientific Research (No.17591927) and Grant-in-Aid for Young Scientists (B: 19791462) from the JSPS, Japan, and the Frontier Science Projects to LEBRA at Nihon University, 2000 and 2005, from the MEXT, Japan.

\section{References}

1. Nakada H., Sakae T., Machida T., Kato T. and Kobayashi K.: New bone formation pattern of surface blasted implants: Backscattering imaging observation of the rabbit tibia case. J Jpn Soc Oral Implant 16: 477-484, 2003

2. Suwa T., Sakae T., Nakada H., LeGeros R.Z. and Kobayashi K.: Variation in composition of bone surrounding implants. Key Engineering Materials 309-311: 19-22, 2006

3. Suwa T., Sakae T., Nakada H., Kato T. and Kobayashi K.: Crystallinity evaluation of new bone around hydroxyapatiteblasted implants. J Jpn Soc Oral Implant 19: 453-460, 2006, in Japanese

4. Hayakawa Y., Hayakawa K., Inagaki M., Kuwada T., Mori A., Nakao K., Nogami K., Sakae T., Sakai T. and Sato I.: Advanced applications of PXR at LEBRA, Nihon University. Channelling 2006, (in press)

5.Hayakawa Y., Sato I., Hayakawa K., Tanaka T., Mori A., Kuwada T., Sakai T., Nogami K., Nakao K. and Sakae T.: Status of the parametric X-ray generator at LEBRA, Nihon University. Nuclear Instr Methods in Physics Res B, 2006 (in press)

6. Bellucci S. and Biryukov V.: The future looks bright for particle channelling. CERN COURIER 46: 37-38, 2006

7. Sakae T. and Hirai G.: Degree of calcification and crystallinity of immature bovine enamel. J Oral Sci 5: 276-281, 1979, in Japanese

8. Suga S. and Gustafson G.: Studies on the development of rat enamel by means of histochemistry, microradiography, and polarized light microscopy, Proc $9^{\text {th }}$ ORCA Cong Dent Caries, Paris 223-244, 1963

9. Sakae T. and Hirai G.: Calcification and crystallization in bovine enamel. J Dent Res 61: 57-59, 1982 